\title{
International Consensus Conference for Advanced Breast Cancer, Lisbon 2019: ABC5 Consensus - Assessment by a German Group of Experts
}

\author{
Christoph Thomssen $^{a}$ Diana Lüftner ${ }^{b}$ Michael Untch ${ }^{c}$ Renate Haidinger ${ }^{d}$ Rachel Würstlein ${ }^{e}$ \\ Nadia Harbeck $^{\mathrm{e}}$ Doris Augustin ${ }^{f}$ Susanne Briest ${ }^{g}$ Johannes Ettl ${ }^{\text {h }}$ Peter A. Fasching ${ }^{i}$ Frank Förster $^{j}$ \\ Christian M. Kurbacherk Hans-Joachim Lück' Norbert Marschner ${ }^{\mathrm{m}}$ Lothar Müller ${ }^{\mathrm{n}}$ Volkmar Müller $^{\circ}$ \\ Lidia Perlova-Griffp Isabel Radke ${ }^{q}$ Eugen Ruckhäberle ${ }^{r}$ Iris Scheffen ${ }^{\text {s }}$ Eva Schumacher-Wulf ${ }^{t}$ \\ Moritz Schwoerer $^{\mathrm{u}}$ Dieter Steinfeld-Birg ${ }^{\mathrm{V}}$ Katja Ziegler-Löhrw \\ ${ }^{a}$ Klinik und Poliklinik für Gynäkologie, Martin-Luther-Universität Halle-Wittenberg, Halle an der Saale, Germany; ${ }^{b}$ Medical \\ Department of Hematology, Oncology, and Tumor Immunology, Charité Berlin, Campus Benjamin Franklin, Berlin, Germany; \\ ${ }^{c}$ Clinic of Gynecology and Obstetrics, Multidisciplinary Breast Cancer Center, Department of Gynecologic Oncology, HELIOS

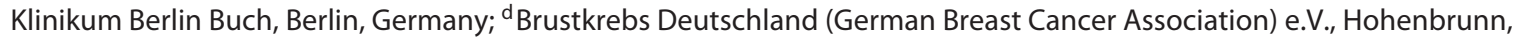

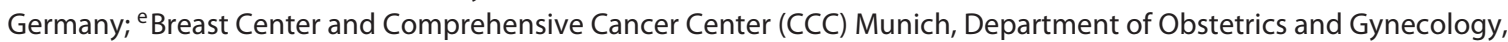 \\ University of Munich (LMU), Munich, Germany; ${ }^{\mathrm{f} B r e a s t}$ Center of Eastern Bavaria, DONAUISAR Hospital of Deggendorf,

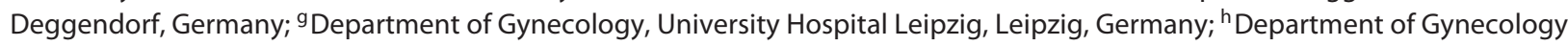 \\ and Obstetrics, University Hospital Rechts der Isar, Munich, Germany; 'Women's Hospital at the University Hospital Erlangen, \\ Comprehensive Cancer Center Erlangen-EMN, Friedrich-Alexander University Erlangen-Nuremberg, Erlangen-Nuremberg, \\ Germany; 'Practice for Gynecology and Obstetrics, Gynecological Oncology and Palliative Care, Poliklinik gGmbH, Chemnitz, \\ Germany; ${ }^{k}$ Practice - Gynecology I (Gynecologic Oncology), Gynecologic Center Bonn-Friedensplatz, Bonn, Germany; 'Practice \\ for Hemato-Oncology, Hannover, Germany; ${ }^{m}$ Joint Practice for Interdisciplinary Oncology and Hematology, Freiburg, Germany; \\ ${ }^{n}$ Oncology Specialist Practice of Leer-Emden-Papenburg, Leer-Emden-Papenburg, Germany; ${ }^{\circ}$ Department of Gynecology, \\ University Hospital, Hamburg-Eppendorf, Germany; ${ }^{\mathrm{P}}$ Gynecological Oncology of Wilmersdorf, Treatment Center II of the \\ St. Gertrude Hospital, Berlin, Germany; ${ }^{\mathrm{a} B r e a s t}$ Center, University Hospital of Münster, Münster, Germany; ${ }^{r}$ Department of \\ Obstetrics and Gynecology, University Hospital Düsseldorf, Düsseldorf, Germany; ${ }^{5}$ Breast Center at St. Elisabeth Hospital,

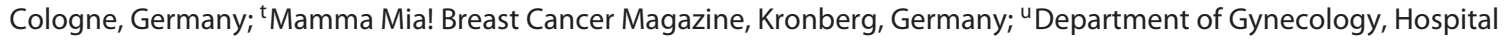 \\ Fürstenfeldbruck, Fürstenfeldbruck, Germany; ${ }^{\vee}$ Practice for Gynecological Oncology, Augsburg, Germany; ${ }^{\text {w Practice for }}$ \\ Gynecological Oncology, Cologne, Germany
}

\section{Keywords}

5th International Consensus Conference for Advanced Breast Cancer · Advanced breast cancer · Hormone receptor-positive and HER2-positive advanced breast cancer - BRCA-associated advanced breast cancer . Triple-negative advanced breast cancer · Personalized medicine

C.T.: $A B C$ panel member, $A B C$ scientific committee member; R.H.: patient advocate; N.H.: ABC panel member.

Steering Committee: D.A., S.B., J.E., P.A.F., F.F., C.M.K., H.-J.L., N.M., L.M., V.M., L.P.-G., I.R., E.R., I.S., E.S.-W., M.S., D.S.-B., and K.Z.-L.

\begin{abstract}
The 5th International Consensus Conference for Advanced Breast Cancer (ABC5) took place on November 14-16, 2019, in Lisbon, Portugal. Its aim is to standardize the treatment of advanced breast cancer based on the available evidence and to ensure that all breast cancer patients worldwide receive adequate treatment and access to new therapies. This year, the conference focused on developments and study results in the treatment of patients with hormone receptor-positive/HER2-negative breast cancer as well as precision medicine. As in previous years, patient advocates from around the world were integrated into the $A B C$ conference and had
\end{abstract}

Prof. Dr. med. Christoph Thomssen

Klinik und Poliklinik für Gynäkologie, Martin-Luther-Universität Halle-Wittenberg Ernst-Grube-Strasse 40

DE-06097 Halle/Saale (Germany)

christoph.thomssen@uk-halle.de 
seats on the $A B C$ consensus panel. In the present paper, a working group of German breast cancer experts comments on the results of the on-site $A B C 5$ consensus votes by $A B C$ panelists regarding their applicability for routine treatment in Germany. These comments take the recommendations of the Breast Committee of the Gynecological Oncology Working Group (Arbeitsgemeinschaft Gynäkologische Onkologie; AGO) into account. The report and assessment presented here pertain to the preliminary results of the $A B C 5$ consensus. The final version of the statements will be published in Annals of Oncology and The Breast.

(c) 2020 S. Karger AG, Basel

\section{Introduction}

The International Consensus Conference for Advanced Breast Cancer (ABC) on diagnosis and treatment of advanced breast cancer takes place every 2 years in Lisbon, Portugal. The now 5th Consensus Conference (ABC5) was held on November 14-16, 2019. The ABC consensus is intended to harmonize and standardize the treatment of patients with locally advanced or metastatic breast cancer internationally. The goal is to make medically necessary therapies available worldwide.

The consensus is developed by an international and interdisciplinary group of experts. This year the panel for the ABC5 consensus consisted of 44 breast cancer experts, including 4 patient advocates, 1 oncology nurse, and 1 psychooncologist (see Box). As in previous years (ABC1-4), 2 breast cancer experts from Germany, i.e., Nadia Harbeck (Munich) and Christoph Thomssen (Halle [Saale]), were members of the ABC panel. In addition, Renate Haidinger was the first patient advocate from Germany to be included in the ABC panel. Christoph Thomssen was also 1 of 4 members of the ABC5 Scientific Committee.

\section{ABC5 Consensus Discussed from a German \\ Perspective}

The rationale of the present post- $\mathrm{ABC} 5$ publication is to comment on the ABC5 voting results in light of German treatment recommendations, specifically the annually updated treatment recommendations of the Breast Committee of the Gynecological Oncology Working Group (AGO) [1], and to adapt the results for routine clinical practice in Germany. This seems advisable since the results of the ABC panel's votes are based on the opinion of international experts from different fields, and country-specific aspects cannot be excluded. The German expert group focused on the on-site voting results. The ABC5 panel's subsequent modifications in view of the planned consensus publication could therefore not be taken into account.

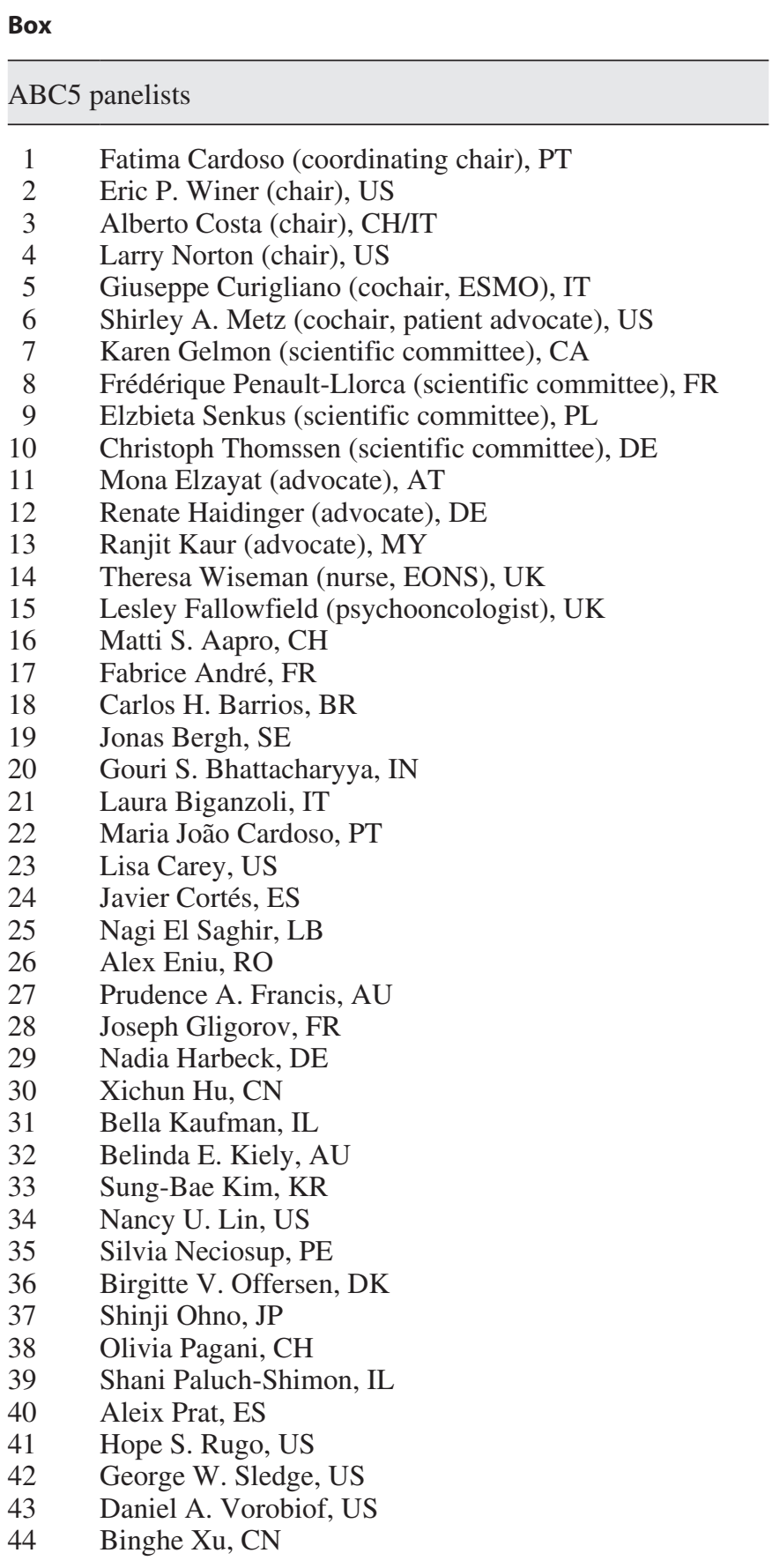

New developments in and current study data on the treatment of advanced and metastatic breast cancer were the focus of the ABC5 consensus. The on-site consensus votes pertained exclusively to new and/or modified statements. Where the content remained unchanged, reference is made to the ABC4 consensus of 2017 and the corresponding consensus paper [2]. ABC statements not discussed continue to be valid. The decisions of the panelists are based on medical research data, regardless of whether a treatment option is available in every country. Questions of health policy were not discussed as part of the consensus. 
Table 1. Level of evidence grading system used by the ABC5 panelists [48]

Level of evidence

I Evidence from at least 1 large randomized, controlled trial of good methodological quality (low potential for bias) or meta-analyses of well-conducted randomized trails without heterogeneity

II Small randomized trials or large randomized trials with a suspicion of bias (lower methodological quality) or meta-analyses of such trials or of trials with demonstrated heterogeneity

III Prospective cohort studies

IV Retrospective cohort studies or case-controlled studies

$\mathrm{V}$ Studies without control group, case reports, expert's opinions

Grade of recommendation

A Strong evidence for efficacy with a substantial clinical benefit, strongly recommended

B Strong or moderate evidence for efficacy but with a limited clinical benefit, generally recommended

C Insufficient evidence for efficacy or benefit does not outweigh the risk of the disadvantages (adverse events, costs, etc.), optional

D Moderate evidence against efficacy or for adverse outcome, generally not recommended

E Strong evidence against efficacy or for adverse outcomes, never recommended

Adapted by permission from the Infectious Disease Society of America-United States Public Health Service Grading System [48].

Here the German expert group discusses the new statements and voting results of the $\mathrm{ABC} 5$ consensus and in addition references the post- $\mathrm{ABC} 4$ work which was published after the $\mathrm{ABC} 4$ consensus in 2017 [3]. The comments of the German experts presented here pertain to the on-site-voting of the $\mathrm{ABC} 5$ consensus which is preliminary. As in previous years, the final recommendations of the 2019 ABC5 consensus will be published in Annals of Oncology and The Breast [2, 4-6].

Cooperation with representatives of patient organizations from around the world was again an important objective of the $\mathrm{ABC}$ conference. This cooperation was further intensified. The ABC Conference is organized by the European School of Oncology (ESO) in cooperation with the European Society of Medical Oncology (ESMO). The publication of the finalized $\mathrm{ABC} 5$ consensus will be coordinated with different international expert associations and patient organizations as was done in the previous years.

The statements presented for on-site voting in Lisbon were rated by the panelists with "yes" (approve), "no" (reject), or "abstain." In addition, there was also the option to vote "insufficient data." This option can be chosen if a panel member believes that the available data are insufficient for a vote of yes or no. The grading system of the $\mathrm{ABC} 5$ consensus is based on the ESMO treatment guidelines [7] (Table 1).

\section{ABC5 Consensus General Statements and Definitions}

\section{Definition of "Visceral Crisis"}

In metastatic breast cancer, various medical treatment options are available; the individual indication depends on, among other parameters, the tumor biology and treatment pressure. A great need for treatment exists, for example, in the case of a visceral crisis. According to the ABC5 panelists, this is defined as severe organ dysfunction, which involves severe symptoms and rapid disease progression and can also be assessed by laboratory values.

According to the ABC5 consensus, evidence of visceral metastases is, in itself, not sufficient to define a visceral crisis. Rather, vital organs need to be compromised to such an extent that the use of rapidly and reliably effective therapies is required. The $\mathrm{ABC} 5$ consensus describes a visceral crisis of the liver and lungs as follows:

- A visceral crisis of the liver exists when bilirubin levels increase very rapidly ( $>1.5$ times the upper limit of normal) without the presence of Gilbert syndrome (i.e., Meulengracht syndrome) or a biliary tract obstruction.

- A visceral crisis of the lungs can be assumed when dyspnea at rest increases more rapidly and cannot be relieved by pleural drainage (level of evidence [LoE]: expert opinion/NA).

The German expert group agrees with these ABC5 clarifications of a visceral crisis. The AGO definition may be adapted accordingly [1].

\section{The Challenge of "Long-Term Survival"}

Thanks to new treatment options, an increasing number of patients with advanced and metastatic disease have a chance of surviving for many years. "Precision medicine" may even offer the prospect of long-term survival.

In this context, the challenge is how to envision the follow-up care of these patients. For advanced breast cancer patients whose disease is stable for a long period of time or who are even in complete remission, the majority 
Table 2. Predictive factors for the treatment of metastatic breast cancer according to the AGO recommendation of 2019 version 1.0 [1]

\begin{tabular}{|c|c|c|c|c|}
\hline \multirow[t]{2}{*}{ Therapy } & \multirow[t]{2}{*}{ Factor } & \multicolumn{2}{|c|}{ Oxford } & \multirow{2}{*}{$\begin{array}{l}\text { AGO recommen- } \\
\text { dation }\end{array}$} \\
\hline & & $\mathrm{LoE}^{\mathrm{a}}$ & grading & \\
\hline \multirow[t]{2}{*}{ Endocrine therapy } & \multirow{2}{*}{$\begin{array}{l}\mathrm{ER} / \mathrm{PR} \text { (primary tumor, metastasis), } \\
\text { previous response }\end{array}$} & $1 \mathrm{a}$ & A & ++ \\
\hline & & $2 b$ & $\mathrm{~B}$ & ++ \\
\hline Chemotherapy & previous response & $1 b$ & $\mathrm{~A}$ & ++ \\
\hline Anti-HER2 drugs & HER2 (primary tumor, better metastasis) & la & $\mathrm{A}$ & ++ \\
\hline $\begin{array}{l}\text { Checkpoint inhibitors } \\
\text { (atezolizumab) }\end{array}$ & PD-L1 immune cell ${ }^{\mathrm{C}}$ positivity in TNBC & $1 b$ & $\mathrm{~B}$ & + \\
\hline PARP inhibitors & gBRCA1/2 mutation & 1a & A & ++ \\
\hline Bone-modifying drugs & bone metastasis & 1a & A & ++ \\
\hline Any therapy & CTC monitoring & $1 b$ & A & $++^{\mathrm{b}}$ \\
\hline
\end{tabular}

a Oxford LoE used by AGO differs from the LoE used by the ABC consensus. ${ }^{b}$ Within clinical trials. ${ }^{\mathrm{c}} \geq 1 \%$ on immune cells. PD-L1, programmed cell death ligand 1; TNBC, triple-negative breast cancer; gBRCA 1/2, germline BRCA1/2 gene; CTC, circulating tumor cell.

(83.3\%) of ABC5 panelists recommend also performing adequate imaging of the breast on a regular basis in the context of follow-up examinations. They reference the fact that early breast lesions cannot always be adequately represented using staging computed tomography or PET/ CT scans (LoE/GoR: expert opinion/C).

From a German perspective, breast examinations with subsequent imaging, if needed - are generally a part of staging in patients whose disease is stable [1]. The rationale for this is locoregional assessment. Potential secondary tumors, which may have a different tumor biology, must be detected at an early stage so that the therapy can be adjusted in time.

\section{General Statements on Systemic Treatment}

\section{Factors Relevant to the Treatment Decision}

Tumor biology is becoming increasingly important in treatment decisions. Changes on a molecular level serve as prognostic and/or predictive markers. Determination of hormone receptor (HR) and HER2 status is an established procedure. In addition, the ABC5 panelists (95.1\%) recommend testing tumor tissue for PIK3CA mutations and blood for $g B R C A$ mutations ( $g B R C A$ : germline $\mathrm{BRCA}$ ). In triple-negative breast cancer (TNBC), the expression of PD-L1 (programmed cell death ligand-1) should be tested in the tumor (see Precision Medicine Outlook) (see AGO recommendations in Table 2). According to the $\mathrm{ABC} 5$ consensus, each of these tests should only be performed if the appropriate targeted agents are available, i.e., if the test has a therapeutic consequence.

The treatment decision should also take other factors into account such as: previous therapies and residual toxicities, the disease-free interval, the tumor burden (the number and site of metastases), the patient's biological age and performance status, including potential comorbidities (including organ dysfunctions), the menopausal status (with regard to endocrine therapy), if applicable, the urgency of treatment (the need for a rapid response and symptom control), socioeconomic and psychological factors, patient preference, and the availability of therapies (LoE/GoR: expert opinion/A).

The German experts note that the list of factors that are relevant for treatment decisions is subject to continuous change and needs to be updated regularly, incorporating current study data (including survival data) and approvals. In light of the German perspective, the list provided by the ABC5 panelists is already incomplete and should be expanded to include ESR1 mutation testing (suggesting resistance against aromatase inhibitors [AI]) and detection of NTRK (neurotrophic tyrosine receptor kinase) gene fusion (use of selective TRK [tropomyosin receptor kinase] inhibitors). Since October 2019, larotrectinib has been available as the first TRK inhibitor for the treatment of solid tumors with NTRK gene fusion. The German experts assume that tumor-agnostic indications (indications that are not specific to tumor type) will be increasingly important in the near future. NTRK gene fusion is mainly observed in the histological type of secretory breast cancer.

\section{Metronomic Chemotherapy}

The German experts agree with the majority vote of the ABC5 panelists (97.6\%) that metronomic chemotherapy is an option for patients with advanced breast cancer who do not require a rapid tumor response. According to the $\mathrm{ABC} 5$ vote, the combination of low-dose cyclophosphamide and methotrexate and the metronomic use of capecitabine or vinorelbine are possible regimens. From a German perspective, metronomic regimens should only 
be implemented if they are evidence based and have been shown to be as effective as standard regimens. The German experts recommend the following doses and dosage forms for metronomic therapies [8-17]:

- capecitabine $500 \mathrm{mg}, 2-3$ times daily,

- vinorelbine $30 \mathrm{mg}$ daily or every other day,

- cyclophosphamide $50 \mathrm{mg}$ daily plus methotrexate 2.5 mg every other day or alternatively cyclophosphamide $50 \mathrm{mg}$ daily and methrotrexate $2.5 \mathrm{mg}$ b.i.d. on days 1 and 4 each week, and

- VEX regimen: cyclophosphamide $50 \mathrm{mg}$ (orally) daily, capecitabine $500 \mathrm{mg}$ (orally) 3 times a day, and vinorelbine $40 \mathrm{mg}$ (orally) 3 times a week.

\section{Use of Bevacizumab}

The angiogenesis inhibitor bevacizumab is approved in Germany as first-line treatment of metastatic HER2negative breast cancer in combination with paclitaxel or capecitabine. The use of bevacizumab as an add-on to chemotherapy was a controversial topic of discussion among the ABC5 panelists.

According to the proposed $\mathrm{ABC} 5$ statement, the use of bevacizumab (as an add-on to chemotherapy) should be limited to selected cases and is not recommended beyond first- and second-line therapies. To date, no prolongation of survival has been demonstrated prospectively, whereas the potential toxicity is substantial. In controlled clinical trials, treatment for metastatic disease with bevacizumab significantly prolonged the progression-free survival but not the overall survival (OS) [18-20]. The majority (52.6\%) of the $\mathrm{ABC} 5$ panelists rejected this negative statement regarding bevacizumab (5.2\% abstained). However, approval for bevacizumab was withdrawn by the (US Food and Drug Administration (FDA).

The former statement (ABC4 consensus) [3] therefore remains valid but places an emphasis on first-line use of bevacizumab. According to this statement, bevacizumab is an option in metastatic HER2-negative breast cancer in combination with first-line chemotherapy. In the absence of predictive factors, the use of bevacizumab must be decided on an individual basis. This is consistent with the recommendations of the AGO [1]. The German experts support the first-line indication of bevacizumab, which is also consistent with its approval in Europe. They add that the chemotherapy partner also plays a role in the use of bevacizumab.

\section{HR-Positive, HER2-Negative (HR \pm /HER2-) Breast Cancer}

Data concerning the use of CDK4/6 inhibition has increased substantially over the last 2 years since the ABC4 consensus. Prospective study data demonstrating a sur- vival benefit in patients treated with the combination of a CDK4/6 inhibitor and endocrine therapy compared with endocrine therapy alone have become available in the meantime [21, 22]. ABC5 panelists clearly voted in favor of endocrine-based combination therapy with a CDK4/6 inhibitor and defined this as standard of care for $\mathrm{HR}+1$ HER2- advanced breast cancer (97.4\% approval). In addition to the survival benefit, the ABC5 panelists reference the overall good tolerability of CDK4/6-based combination therapy. They emphasize that the patients' health-related quality of life (QoL) is maintained or improved.

CDK4/6 inhibitors might be combined with either AI or fulvestrant. Each combination is applicable in de novo metastatic breast cancer and recurrent advanced breast cancer, as first-line or second-line therapy, regardless of whether the patient has experienced primary or secondary endocrine resistance (see $\mathrm{ABC}$ definition [3]) and regardless of menopausal status. Premenopausal patients require a gonadotropin-releasing hormone $(\mathrm{GnRH})$ agonist in addition. CDK4/6 inhibition is also an effective therapy for men with advanced breast cancer and should preferably be combined with a GnRH agonist in men. The German experts agree with these statements.

\section{Importance of ESMO-MCBS Scores}

As part of the ABC5 consensus, all of the panelists approved the assessment of currently available CDK4/6-inhibitor therapies on the basis of the ESMO-MCBS (ESMO Magnitude of Clinical Benefit Scale) [23], which differentiates between the individual options. The ABC5 panelists justify the different assessment based on the respective study and follow-up data. According to the grading scale, first-line use of ribociclib plus endocrine therapy in premenopausal patients has the highest score (MCBS 5) due to efficacy benefits in median PFS and OS and concurrent improvement in health-related QoL.

The ABC5 consensus statements are based on ESMOMCBS v1.1. [23]. In summary, taking into account the primary study endpoint, therapies with a non-curative intent are graded on 5 levels. An MCBS grade 5 is given only for therapies that result in both a survival gain and improvement of the QoL. Considered a less reliable outcome surrogate, a gain of progression-free survival alone is assessed as an MCBS grade 3. Only grades 4 and 5 are acknowledges to indicate a proven clinical benefit [23-25].

\section{ESMO-MCBS 5}

- First-line therapy with ribociclib plus endocrine therapy in premenopausal patients (efficacy score 4 [PFS/ OS], improved QoL). 


\section{ESMO-MCBS 4}

- Second-line therapy with palbociclib/fulvestrant (efficacy score 3 [PFS/OS], improved QoL)

- First-line and second-line treatment with ribociclib/ fulvestrant (efficacy score 4 [PFS/OS]; no improvement in QoL)

- Second-line therapy with abemaciclib (efficacy score 3 [PFS/OS], no improvement in QoL).

\section{ESMO-MCBS 3}

- First-line treatment with palbociclib (efficacy score 3 [PFS], no improvement in QoL) or abemaciclib (efficacy score 3 [PFS], no data concerning QoL), each in combination with an $\mathrm{AI}$

- First-line treatment with ribociclib/AI in postmenopausal patients (efficacy score 3 [PFS], no improvement in QoL).

The German expert group notes that the ESMO-MCBS is not common in Germany but that its use is becoming more widespread. It is a scoring system used in cliniceconomical or health technology assessments, particularly for new drugs, and it can be used to generally assess the clinical significance of a drug if needed [24, 25]. The ESMO-MCBS does not play a role in individual treatment decisions. For the first-line endocrine therapy of a patient with $\mathrm{HR}+$ advanced breast cancer and good QoL prior to treatment, for instance, the German experts emphasize that the ESMO-MCBS score does not provide meaningful information for an individual treatment decision.

In a homogeneous health system, the German experts claim that the score should not be used to decide for or against a treatment with a specific CDK4/6 inhibitor. The German experts refer to the AGO recommendations [1], where all 3 of the currently available CDK4/6 inhibitors are equally recommended assuming similar clinical efficacy in this substance class.

Overall, the ABC5 voting results clearly indicate that CDK4/6 inhibitors have become a part of routine clinical practice and are accepted as standard treatment. The German experts emphasize that the use of a CDK4/6 inhibitorbased endocrine combination therapy should be discussed with patients with $\mathrm{HR}+/ \mathrm{HER} 2-$ advanced breast cancer.

\section{CDK4/6 Inhibition: In Which Line of Therapy?}

It is currently unclear whether and in which patients CDK4/6 inhibitor-based endocrine combination therapy should be implemented as first-line or second-line therapy. The ABC5 panel voted unanimously $(100 \%)$ for implementing CDK4/6 inhibitors preferentially in the firstline setting and defining them as standard first-line therapy in HR+/HER2-advanced breast cancer. Nevertheless, an endocrine-alone therapy may be indicated as first-line therapy for special patients on the basis of an informed consent. The German experts reference the current AGO recommendation, which defines endocrine-based combination therapy as standard first-line therapy [1]. In Germany, CDK4/6 inhibitors are increasingly being used as first-line therapy in clinical practice [26].

The SONIA trial (NCT03425838), a multicenter, randomized phase III study of an endocrine-based combination therapy with a CDK4/6 inhibitor as first- or secondline therapy and subsequent or prior endocrine-alone therapy in HR+/HER2- advanced breast cancer is currently ongoing. The objective is to compare both sequences using PFS2 as the primary endpoint [27].

\section{No Maintenance Therapy with CDK4/6 Inhibition}

To date, there are no data indicating that the endocrine-based combination with a CDK4/6 inhibitor should be implemented as maintenance therapy after completing chemotherapy (LoE/GoR: NA/D). If maintenance endocrine therapy is an option, endocrine monotherapy is indicated. After an intense discussion, $65.7 \%$ of the ABC5 panelists agreed with this statement.

The German experts note that, in first-line therapy, it must be clarified whether chemotherapy is indicated. If this is the case, the effect of the chemotherapy should be awaited rather than prematurely implementing a highly effective treatment option such as endocrine-based combination therapy with a CDK4/6 inhibitor. The endocrinebased combination with a CDK4/6 inhibitor should only be used in the case of progression after chemotherapy.

\section{Alpelisib in PIK3CA-Mutated Breast Cancer}

In the randomized phase-III SOLAR-1 study, the median progression-free survival of postmenopausal patients with $\mathrm{HR}+/ \mathrm{HER} 2-$ PIK3CA-mutated advanced breast cancer was prolonged by approximately 5 months and thus nearly doubled $(\mathrm{HR}=0.65 ; p<0.001)$ using the PI3K inhibitor alpelisib in combination with fulvestrant [28]. All of the patients included experienced disease progression after prior endocrine therapy. Progression-free survival was the primary study endpoint.

A PIK3CA mutation is detected in $30-40 \%$ of all $\mathrm{HR}+$ / HER2- advanced breast cancers. This leads to increased activation of the $\alpha$-isoform of phosphoinositide- 3 kinase (PI3K), which stimulates tumor growth. In addition, PIK3CA-mutated breast cancer appears to have a poor response to endocrine therapy. PI3K inhibitors like alpelis$\mathrm{ib}$ therefore offer a promising new therapeutic option for this disease. However, alpelisib is currently not (yet) approved in Europe for the treatment of PIK3CA-mutated breast cancer.

Nevertheless, almost $90 \%$ (87.8\%) of the ABC5 panelists already see the combination of alpelisib/fulvestrant as a 
treatment option for postmenopausal patients with $\mathrm{HR}+$ / HER2 - metastatic breast cancer even before approval; prerequisites are that a PIK3CA mutation is present on exon 9 or 20 and that the patient has previously been treated with an $\mathrm{AI}$ and has adequate $\mathrm{HbA}_{1 \mathrm{C}}$-levels. However, the $\mathrm{ABC} 5$ panelists stress that the treatment decision must be subject to a particularly rigorous benefit-risk assessment given the side effect spectrum of alpelisib (risk of therapyinduced diabetes mellitus) and the fact that no survival benefit has yet been demonstrated for the combination. Since only about $7 \%$ of the patients in the SOLAR-1 study had previously been treated with a CDK4/6 inhibitor, it is also unclear how effective the combination is in patients who have previously received a CDK4/6 inhibitor.

The German experts note that no clinical practice recommendation for the treatment of HR+/HER2- metastatic breast cancer can be issued for alpelisib until the drug has been approved. According to study data, treatment with alpelisib in combination with fulvestrant is associated with an increased risk of hyperglycemia. Although patients with diabetes mellitus were not enrolled in the SOLAR-1 study, approximately one third of the patients experienced grade 3 hyperglycemia, which can be managed with oral antidiabetic drugs but also resulted in discontinuation of treatment [28].

The German experts agree with the ABC5 panelists in that a non-sedating antihistamine should be given concurrently with alpelisib therapy. There is an increased risk of skin complications (rash) in the first 2 weeks after starting therapy. The antihistamine can usually be discontinued after 4 weeks.

\section{Endocrine Therapy Sequence: Numerous Options}

An optimal endocrine therapy sequence is not currently defined. It depends on, among other things, previous treatment, tumor burden, and patient preference. According to the ABC5 panel, possible treatment options include endocrine-based combination therapies (AI or fulvestrant) with a CDK4/6 inhibitor or with fulvestrant or tamoxifen plus everolimus, endocrine monotherapy (AI, fulvestrant, and tamoxifen), and the combination of fulvestrant/alpelisib (if a PIK3CA mutation has been detected). For subsequent lines of therapy, the ABC5 panelists see megestrol acetate and estradiol and, if applicable, another endocrine therapy as options.

The German experts generally agree with the ABC5 panelists, adding that the therapy sequence also depends on the quality of the response to previous therapies. The use of progestins and low-dose estrogens is obsolete in Germany due to potentially severe side effects and the large number of treatment alternatives. The German experts note the fact that there is currently no evidencebased data to support the continuation of endocrinebased therapy (treatment beyond progression; continua- tion of CDK4/6 or mTOR inhibitor, change of endocrine combination partner). Alpelisib in combination with fulvestrant is only an option for PIK3CA-mutated tumors after approval.

In a separate statement focusing on later lines of therapy, the majority (97.5\%) of the ABC5 panelists voted in favor of monotherapy with abemaciclib as an alternative treatment option for endocrine monotherapy after the second-line treatment. In this context, the ABC5 panelists note that reinduction of therapy is frequently considered an option and implemented in routine clinical practice even though there are no robust data to support this approach. The latter is consistent with the above comments by the German expert group and the AGO recommendations [1].

\section{Endocrine-Based Combination or Chemotherapy?}

Clinical studies comparing endocrine-based combination therapy with single-agent chemotherapy in patients with metastatic HR+/HER2- breast cancer are currently ongoing. Initial results from randomized phase II studies indicate that endocrine-based combinations are equal or even superior to single-agent chemotherapy with regard to efficacy and safety (LoE/GoR: II/B) [29, 30]. The ABC5 panelists consider endocrine-based combination therapy to be the preferable treatment option in case of HR+/HER2metastatic breast cancer. The German experts agree.

\section{Nonsteroidal AI Plus Fulvestrant}

In a US-based phase III study conducted by the Southwest Oncology Group (SWOG S0226; NCT00075764), the endocrine combination of a nonsteroidal AI (anastrozole) and fulvestrant was shown to significantly improve both PFS and OS in direct comparison with AI monotherapy (anastrozole) in postmenopausal patients with HR+/HER2- metastatic breast cancer [31]. However, other studies with a comparable design were unable to confirm this benefit $[32,33]$.

According to the subgroup analysis of the SWOG study [31], the PFS/OS benefit is limited to patients who are endocrine naive and have not received prior adjuvant hormonal therapy (tamoxifen). Therefore, endocrine combination therapy may only be an option for this subgroup of patients. This statement was vigorously discussed by the ABC5 panelists on site. Almost two thirds $(60.0 \%)$ of the ABC5 panelists believe that endocrine combination therapy is only an option if an endocrinebased combination therapy with a CDK4/6 inhibitor is not available, including for the mentioned subgroup (no prior adjuvant endocrine therapy).

From the German perspective, the data from the SWOG study are not relevant to clinical practice in Germany. The German experts refer to the consistent data and study results for CDK4/6 inhibitors. Two studies have already
Thomssen et al. 
demonstrated a significant survival benefit in this context $[21,22]$. The SWOG study has the following flaws [21]: (1) the standard dose of fulvestrant is $500 \mathrm{mg}$, and thus $250 \mathrm{mg}$ - as used in the trial - is too low, and (2) the PFS/ OS benefit was only significant in the subgroup of patients who had not received prior endocrine therapy.

\section{HER2-Positive Breast Cancer: Use of Neratinib}

The combination of neratinib/capecitabine is currently not approved for the treatment of HER2-positive $(\mathrm{HER} 2+)$ metastatic breast cancer. In the randomized phase III study NALA [34], the combination achieved a median PFS benefit of 2.2 months but no significant survival benefit versus the combination of lapatinib/ capecitabine in patients with HER2+ metastatic breast cancer who had received multiple prior therapies. Lapatinib/capecitabine is a standard third-line option for HER2+ metastatic breast cancer [1].

The ABC5 panelists agreed (90\%) that, currently, they would not recommend the combination of neratinib/ capecitabine for routine use in clinical practice for the setting discussed above (LoE/GoR: I/D). They emphasized the need for further clinical trials to validate the potential role of the combination in advanced breast cancer, including in patients with brain metastases. In their statement, they also note that neratinib/capecitabine was not compared with trastuzumab/capecitabine. Trastuzumab/ capecitabine, in turn, has demonstrated a survival benefit compared to lapatinib/capecitabine [35].

According to the German perspective, a statement on the clinical use of neratinib/capecitabine in HER2 + metastatic breast cancer is unnecessary since the combination is currently not approved. If once approved, neratinib/ capecitabine would be a potential option for a later line therapy in HER2+ metastatic breast cancer.

\section{TNBC: Role of Immunotherapy}

Atezolizumab/nab-paclitaxel is the first available immunotherapy/chemotherapy combination for first-line treatment of patients with metastatic (ER-, PR-, and HER2-) and PD-L1 expression on immune cells (PD-L1/ IC $\geq 1 \%$, assessed using the Ventana SP142 antibody) [1]. Ninety-five percent (94.8\%) of the ABC5 panelists consider the combination of atezolizumab/nab-paclitaxel as a treatment option for first-line therapy in $\mathrm{PD}-\mathrm{L} 1 / \mathrm{IC}+$ advanced TNBC (MCBS 3; LoE/GoR: I/B). In the phase III pivotal IMpassion-130 study [36], the combination achieved significantly prolonged PFS for patients with PD-L1+ advanced TNBC (HR 0.62; $p<0.0001$ ) versus chemotherapy alone (nab-paclitaxel). PFS was the prima- ry study endpoint. The final survival data are not available yet. At the time of evaluation, a numerical survival benefit was seen in favor of atezolizumab $(\mathrm{HR}=0.62)$ [36].

The use of immunotherapy as monotherapy in a later treatment line in advanced TNBC is not considered an option by the ABC5 panelists (89.4\%) since response rates are low (LoE/GoR: I/E). In principle, the German experts agree, and they emphasize that first-line use of atezolizumab/nab-paclitaxel should generally be preferred. In light of the data from the KEYNOTE-119 (KN-119) study [37], the German experts believe that, in individual cases, it could be an option to administer a monotherapy with pembrolizumab, for example, instead of single-agent chemotherapy in patients who have received multiple prior therapies. A combined positive score $\geq 20 \%$ in the tumor tissue would be a prerequisite based on KN-119 data. It should be emphasized, however, that single-agent pembrolizumab is not yet approved for the treatment of metastatic TNBC in Germany.

The ABC5 panelists (97.5\%) and the German experts agree that, outside of clinical trials, immunotherapy is currently not an option for patients with subtypes of advanced breast cancer other than TNBC. Results of ongoing studies need to be awaited (LoE/GoR: NA/E).

\section{Focus on Germline BRCA Testing}

The German experts agree with the ABC5 panelists' vote that $g B R C A$ (germline BRCA) mutation testing is indicated at an early stage of advanced breast cancer since the test result has therapeutic consequences. Panel testing is indicated in patients with a family history of breast and/ or ovarian cancer and in TNBC-patients $\leq 60$ years (in Germany testing is only reimbursed for patients younger than 50 years) independent of family history. The German experts note that a poly (ADP-ribose) polymerase (PARP) inhibitor is indicated if a $g B R C A$ mutation is detected. They also note that, in the event of a positive $g B R C A$ test, the patient's family should be informed (subject to patient consent) and genetic counseling needs to be offered. In the case of metastatic breast cancer, patient age and the HR status of the tumor are irrelevant for $g B R C A$ testing. Even if the incidence of a $g B R C A$ mutation is lower in older women, it remains therapeutically relevant. The German experts emphasize that for therapeutic purposes only BRCA1/2 should be tested.

\section{Use of PARP Inhibitors}

For patients with HER2-negative advanced breast cancer harboring a $g B R C A$ mutation, 2 PARP inhibitors, i.e., olaparib and talazoparib (not yet marketed in Germany), have been available as a treatment option since 2019. The patients should previously have been treated with an an- 
Table 3. Actionable genomic alterations relevant for the treatment decision according to the AGO recommendation of 2019 version 1.0 [1]

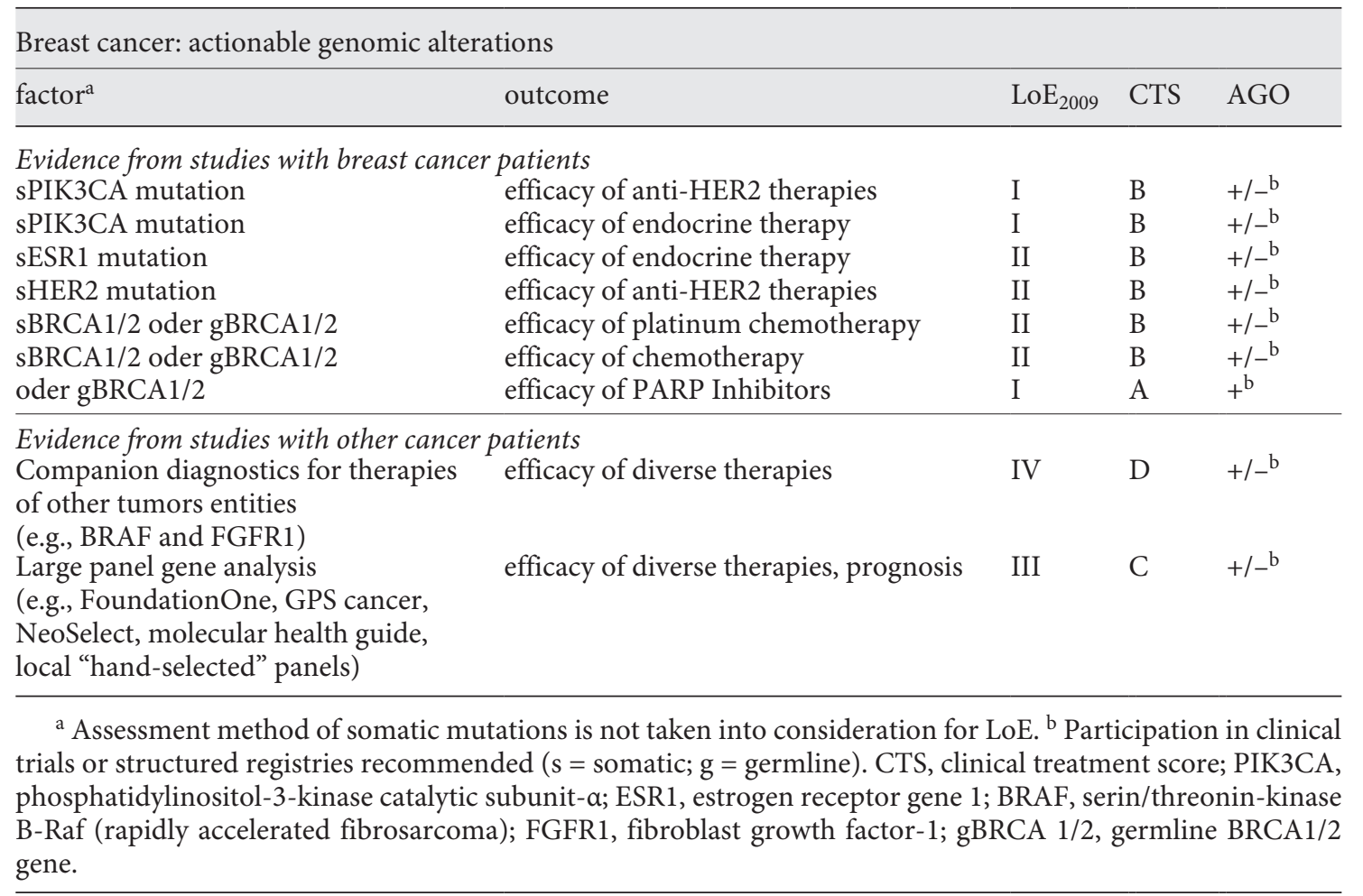

thracycline and/or taxane and, if applicable, endocrine therapy in the (neo)adjuvant or metastatic setting. If chemotherapy is indicated in these patients, the majority (78.0\%) of the ABC5 panelists recommend first administering a PARP inhibitor. Chemotherapy should not be administered until the PARP inhibitor has failed. In their statement, the ABC5 panelists note that, according to the data $[38,39]$, the PARP inhibitors achieve a longer median PFS than chemotherapy while also having a more favorable side effect profile and that this is therefore reflected in improved health-related QoL (MCBS 4; LoE/GoR: I/A).

The German experts agree that a PARP inhibitor should be administered as early as possible in HER2-negative advanced breast cancer. To date, a survival benefit has only been demonstrated in the OlympiAD study in the first-line setting [38]. Since these data come from an analysis of a rather small subgroup, additional survival data should be generated. According to the German perspective, it is regrettable that the $g B R C A$ mutation analysis is currently not performed nationwide and across the board in HER2- advanced breast cancer [40].

\section{Therapy Sequence when gBRCA Mutation Has Been Detected}

Currently, we do not have sufficient data regarding the optimal therapy sequence for patients with a $g B R C A$ mutation and HER2-negative advanced breast cancer. This is also true for HR-positive $g B R C A$-associated advanced breast cancer. However, in light of the survival benefit that has now been documented for endocrine-based combination therapy with a CDK4/6 inhibitor [21, 22], the majority (90.2\%) of the ABC5 panel recommend initial administration of an endocrine-based combination with a CDK4/6 inhibitor and using a PARP inhibitor in the second-line setting. The German experts agree. The therapy sequence question must be further evaluated.

In the randomized phase III BROCADE-3 study [41], a PARP inhibitor (veliparib) was used as maintenance therapy in $g B R C A$-mutated metastatic breast cancer for the first time after successful platinum-based chemotherapy. One-quarter of patients receiving veliparib maintenance therapy remained progression-free after 3 years. Since veliparib is currently not approved, the panel consciously declined to vote on the relevance of this approach.

\section{Precision Medicine Outlook}

Precision medicine is a new therapeutic approach in oncology. It focuses on genomic and molecular changes that serve as prognostic and/or predictive markers, underlie tumor development, and promote proliferation and metastasis. Genomic/molecular changes/mutations are also often the target by new agents (see AGO in Tables 2, 3). 
Value of circulating tumor DNA Analysis

- The ABC5 panelists (97.2\%) and German experts agree that the detection of circulating tumor DNA (ctDNA) in the blood of cancer patients is currently not ready for routine clinical use for an early and reliable detection of tumor progression.

- However, the majority (92.6\%) of the ABC5 panelists see ctDNA analysis as an option for detecting a PIK3CA mutation in order to reach an appropriate treatment decision (e.g., use of alpelisib) (LoE/GoR: II/A). The German experts reiterate that alpelisib is currently not approved and that thus there is no need for ctDNA analysis at the moment. The German experts recommend a mutation analysis in the tumor tissue, if applicable. This can be requested from the pathologist in individual cases. If a PIK3CA mutation is detected, the German experts recommend considering participation in the Managed Access Program (MAP) for alpelisib.

- The German experts agree with the ABC5 statement that a PIK3CA mutation test (exon $9+20$ ) should be performed on tumor tissue (primary tumor or metastasis) or by means of $c t D N A$ analysis as soon as alpelis$\mathrm{ib}$ is approved. However, $c t D N A$ mutation analysis is neither extensively used nor validated in Germany. If no tumor tissue samples have been archived and an uninformative result has been obtained from a liquid biopsy test, a PIK3CA mutation test should be performed on a fresh tumor biopsy (LoE/GoR: I/B).

\section{No Recommendation for ESR1 Mutation Testing?}

According to the ABC5 consensus, ESR1 mutational status does not currently play a role in routine clinical practice and treatment of $\mathrm{HR}+$ advanced breast cancer. Routine ESR1 mutation testing is therefore not recommended. Over $90 \%$ of the ABC5 panelists (90.2\%) do not see a need for ESR1 mutation testing either in determining disease progression or in choosing an endocrine therapy (switching from AI to fulvestrant or novel SERD [selective estrogen receptor degraders]) (LoE/GoR: I/D). The German experts add that the significance of ESR1 mutational status for the use of CDK4/6-inhibitor therapy is unclear, and therefore the significance of ESR1 mutation testing is not defined in Germany. Retrospective data suggest a reduced effectiveness of AI monotherapy. This requires further validation.

\section{TNBC: Recommendation for PD-L1 Testing}

In light of the approval of atezolizumab/nab-paclitaxel as first-line therapy for patients with PD-L1IC+ advanced $\mathrm{TNBC}$, the experts agree that $\mathrm{PD}-\mathrm{L} 1$ testing should be performed in advanced TNBC. The ABC5 panelists only recommend such testing if atezolizumab/nabpaclitaxel is indeed available for clinical use (LoE/GoR: I/A). The ABC5 panelists (97.4\%) recommend Ventana's companion diagnostic test with the SP142 antibody, which was used in the pivotal IMpassion-130 study [36]. A tumor is considered $\mathrm{PD}-\mathrm{L} 1$ positive if $\geq 1 \%$ immune cells are stained for PD-L1 (LoE/GoR: I/A).

The German experts add that different testing methods are required for the different checkpoint inhibitors. For this reason, it is important to discuss this with the local pathology department. The testing method validated in the context of the studies and/or the approval is listed in the relevant product information and must be taken into account. Divergent testing methods must be validated and reconciled with the original procedure.

\section{Procedure in the Case of Low Positive HR Status}

Endocrine-based therapy is considered first-choice for patients with HR+/HER2- advanced breast cancer. However, for cases with low HR expression (ER-positive cells: $1-10 \%)$, the majority (94.8\%) of ABC5 panelists recommend not focusing exclusively on endocrine-based treatment options. These tumors have a similar biology as advanced TNBC (LoE/GoR: III/B).

The German experts agree and reference the treatment recommendations of the AGO [1] and the BrainMet Register Study of the BMBC (Brain Metastases in Breast Cancer Network Germany) initiated by the German Breast Group (GBG) [42]. In these recommendations, the group of breast cancer patients with a "low HR-positive status" is considered a special subgroup and defined as having "questionable endocrine sensitivity." According to the AGO recommendations, these patients may be treated with endocrine-based therapy. However, the success of this therapy should be closely monitored. The majority of these cancers are biologically more similar to basal-like breast cancer. The German experts therefore advocate inclusion of patients with "low HR-positive" $(\mathrm{ER}<10 \%)$ advanced breast cancer in clinical trials for TNBC in order to validate the response to therapy.

\section{Specific Metastatic Sites}

\section{Bone Metastasis}

With regard to bone metastasis and the use of "bonemodifying" agents, the ABC5 panelists reference the ESMO Clinical Practice Guidelines on supportive therapy [43], which are essentially consistent with the recommendations of the AGO Breast (Committee) [1]. According to these guidelines, patients with advanced breast cancer and bone metastasis should routinely be treated with bisphosphonate or denosumab as an add-on to the oncological systemic therapy (LoE/GoR: I/A). Patients who have received zoledronic acid every 4 weeks for 6-12 months and whose disease is stable may be switched to a 3-monthly administration (LoE/GoR: I/B). Due to lack- 
ing evidence, this does not apply to denosumab (LoE/ GoR: NA/D).

If there are no contraindications, calcium and, above all, vitamin $\mathrm{D}_{3}$ should also be supplemented (LoE/GoR: I/A). Supplementation of calcium and vitamin $\mathrm{D}_{3}$ is mandatory for treatment with denosumab. If this is not possible, due to contraindications, for example, denosumab may not be used.

The optimal duration of bone-modifying therapy is currently unclear. In cases of long-standing stable disease with a long overall therapy duration, the risk of osteonecrosis of the jaw and skeletal-related events such as bone fractures increases. In these situations, longer treatment intervals (e.g., 3-monthly bisphosphonate administration) should be considered and discussed with the patient $[44,45]$.

\section{Leptomeningeal Disease}

Leptomeningeal disease is a rare but serious type of metastatic spread that may involve pronounced neurological complications. There is currently no standard procedure for this situation. Aside from best supportive care, radiotherapy or chemotherapy are possible treatment options according to the $\mathrm{ABC} 5$ consensus. The treatment decision should be achieved by an interdisciplinary team (tumor board) taking also into account the prognosis (LoE/GoR: expert opinion). The ABC5 panelists recommend focal radiation in the case of clearly defined, specifically symptomatic lesions. Whole brain radiotherapy may be considered in the case of extensive nodular or symptomatic leptomeningeal disease (in each case, LoE/ GoR: expert opinion). The German experts agree.

The ABC5 panelists note that the patients should not expect a survival benefit or an improvement in their QoL when chemotherapy (if chemotherapy is indicated) is additionally applied directly into the cerebrospinal fluid (intrathecally). In their statement, they note that cerebrospinal fluid progression is also not delayed in a clinically relevant manner by intrathecal chemotherapy (LoE/GoR: II/D).

The German experts agree and add that the indication for intrathecal chemotherapy should be very strictly defined. They agree with the $\mathrm{ABC} 5$ panelists that intrathecal chemotherapy should be only considered in patients with stable systemic disease and normal cerebrospinal fluid flow, if at all. The risk of potentially substantial side effects must be considered and weighed for the therapy decision (LoE/ GoR: expert opinion). The German experts reference the statements in the S3 Breast Cancer Guidelines [46].

\section{Supportive and Palliative Measures}

\section{Use of Cannabis and Opioids}

The use of cannabis for controlling pain has been discussed in the field of oncology for years. The ABC5 pan- elists (97.1\%) stress that the relevance of cannabis for controlling pain and symptoms should be further investigated. The panel notes that cannabis cannot, in any case, replace evidence-based pain therapy, such as morphine (LoE/GoR: I/C).

The German experts agree and add that pain therapy should be administered according to the standards of the German S3 guideline for palliative care [47]. Cannabinoids are accepted as coanalgesics in this guideline but are not a substitute for morphine preparations.

The ABC5 panelists and the German expert group are aware that not all cancer patients in all countries worldwide have unlimited access to morphine preparations. Access to adequate pain control and morphine preparations must be established worldwide.

\section{Managing Gynecological Complaints}

The German expert group absolutely agrees with the ABC5 consensus statements on management of gynecological complaints. According to these statements, hormone replacement therapy is not indicated for the treatment of postmenopausal symptoms in patients with advanced breast cancer. This particularly applies to patients with $\mathrm{HR}+$ advanced breast cancer.

The ABC5 panelists consider the following measures to be valid alternatives:

- Postmenopausal symptoms generally: mind-body interventions, exercise, and cognitive behavioral therapy are effective nonpharmacological options (LoE/GoR: I/B)

- Hot flashes: pharmacological options include venlafaxine, oxybutynin, gabapentin, and clonidine (LoE/ GoR: I/B)

- Sleep disturbances: melatonin may be helpful (LoE/ GoR: II/C).

There is no compelling evidence indicating that phytopharmaceuticals improve postmenopausal symptoms. In addition, potential drug interactions need to be considered (LoE/GoR: I/D).

\section{Sexual Health/Sex Life}

For the first time, the topic of breast cancer patients' sexuality and sexual health is addressed by the ABC 5 consensus. The ABC5 panelists highlight the importance of this topic, with respect to how uncertainty and shame need to be overcome. They note that sexual activity is not limited to sexual intercourse and needs to be perceived in much broader terms. In light of the potentially limited life expectancy of patients with advanced breast cancer, physical contact, affection, emotional support, and empathetic conversations are particularly important.

For many patients, the disease is associated with a deterioration of sexual health. These women require special attention. In many cases, honest conversations and suggestions can help to improve the situation, which also has 
a positive impact on the patient's QoL. The ABC5 panelists recommend the use of standardized measurement instruments (validated questionnaires) that can help to assess the extent to which the patient is negatively impacted (LoE/GoR: expert opinion).

\section{Managing Dyspareunia}

A common cause of dyspareunia is a dry vagina. The $\mathrm{ABC} 5$ panelists recommend hormone-free lubricants as a primary measure (LoE/GoR: II/B). Alternatively, vaginal administration of low-dose estriol preparations is an option (LoE/GoR: II/B). It is unclear whether a local testosterone application is helpful. The German expert group agrees with each point.

\section{ABC5: Patient Advocate Statement}

The ABC Conference specifically promotes communication between patient advocates and members of the medical profession. Therefore, as in previous years, patient advocates from Europe, Asia, the Middle East, Africa, Australia, and North, South, and Central America also attended the $\mathrm{ABC} 5$ Conference and expressed their concerns and requests. The panelist and patient advocate Shirley A. Mertz from the USA presented patient advocates' most important concerns during the ABC5 Conference plenary session.

Mertz explained that having cancer is like surfing. The goal is not to fall off of the surfboard, and the question is how best to accomplish this. To provide individualized treatment and support, it is important for the physician to see the patient as a person and not merely to treat the disease. A consultation of $10-15 \mathrm{~min}$ is not enough for this. "Give patients the opportunity to talk and get to know their fears, desires, and hopes," Mertz urged. In reaching a treatment decision, it is important to know what kind of person the patient is.

It is important to use comprehensible language so that the medical options can be discussed with the patient. Most patients want to know why a certain treatment decision has been reached, and they generally want to be involved in the decision. Mertz said: "Make us your partner in the fight against cancer."

The conversation between physician and patient should always start with a personal lead-in, Mertz enjoined. "Ask us how we feel, how we are handling the therapy, whether we have pain or other complaints, and take them serious." Medical results and further procedures should only be discussed after this.

Mertz reminded physicians that advanced cancer, in particular knowing that a cure is no longer possible, is psychologically challenging for the patient. "Put yourself in our position and try to understand our needs and vulnerabilities."

ABC5 Consensus - Assessment by a

German Group of Experts
Physicians and patients should try to understand each other. "We know that our disease is also a challenge for the physician," Mertz summed up. Mutual understanding and honest conversations are an important foundation for both sides of a good doctor-patient relationship, she asserted. On behalf of all patient advocates, Mertz expressed her thanks for the opportunity to participate in the $\mathrm{ABC} 5$ Conference and the international exchange among the patient advocates themselves and with the physicians.

Following des $\mathrm{ABC} 5$ consensus meeting the $\mathrm{ABC}$ Global Alliance met, which was initiated by the ESO in 2016. The goal of this platform is to unite the ABC community by catalyzing change to improve outcome and extend the lives of women and men living with $A B C$ in all countries worldwide. This year panelist and patient advocate Renate Haidinger (Germany) was elected director of the General Assembly of the ABC Global Alliance.

\section{Conclusion and Outlook}

The ABC5 Conference is a platform for important discussions on the most recent developments in advanced and metastatic breast cancer. The ABC consensus makes an important contribution in terms of standardizing the treatment of advanced breast cancer on an international level and optimizing treatment worldwide. The ABC Conference is therefore complementary to the St. Gallen Consensus Conference on early breast cancer. The next ABC6 Consensus Conference will take place on November 4-6, 2021, in Lisbon, Portugal.

\section{Acknowledgement}

The meeting of the German experts in Lisbon was supported and organized by AURIKAMED Institut GmbH. The authors would like to thank Birgit-Kristin Pohlmann, Nordkirchen, for editing this paper.

\section{Disclosure Statement}

Prof. Christoph Thomssen received honoraria from Amgen, AstraZeneca, Celgene, Daiichi-Sankyo, Eisai, Lilly, MSD, Mundipharma, MEDA, Novartis, Roche, Tesaro, and Vifor.

Prof. Diana Lüftner received honoraria from AstraZeneca, Celgene, Pfizer, Novartis, Amgen, Roche, Loreal, Teva, Tesaro, and Eli Lilly.

Prof. Michael Untch received honoraria to the employer (for AdBoard participation, presentations) and travel grants from Amgen, AstraZeneca, BMS, Celgene, Daiichi Sankyo, Eisai, Janssen Cilag, Johnson \& Johnson, Lilly Deutschland, Lilly International, MSD Merck, Mundipharma, Myriad Genetics, Odonate, Pfizer, PUMA Biotechnology, Riemser, Roche, Sanofi Aventis, Sividon Diagnostics, and TEVA Pharmaceuticals Ind. Ltd. 
Renate Haidinger, Dr. med. Doris Augustin, Dr. med. Susanne Briest, Dr. med. Lidia Perlova-Griff, Prof. Hans-Joachim Lück, Dr. med. Norbert Marschner, and Eva Schumacher-Wulf have no conflict of interests.

PD Dr. med. Rachel Würstlein received honoraria from Agendia, Amgen, AstraZeneca, Boehringer Ingelheim, Carl Zeiss, Celgene, Daiichi Sankyo, Eisai, Genomic Health, GSK, Lilly, MSD, Mundipharma, NanoString, Novartis, Odonate, Paxman, Palleos, Pfizer, Pierre Fabre, Puma Biotechnology, Riemser, Roche, Sandoz/Hexal, Seattle Genetics, Tesaro Bio, and Teva.

Prof. Nadia Harbeck received honoraria for consulting and/or lectures from Agendia, Amgen, Astra Zeneca Celgene, Genomic Health, Lilly, MSD, Novartis, Odonate, Pfizer, Roche, Sandoz/ Hexal, and Seattle Genetics.

Dr. med. Johannes Ettl received honoraria from Astra Zeneca, Roche, Celgene, Novartis, Lilly, Pfizer, Pierre Fabre, TEVA and travel support from Celgene, Lily, Novartis, Pfizer, TEVA, and Pierre Fabre.

Prof. Peter A. Fasching received honoraria from Roche, Pfizer, Celgene, Daiichi-Sankyo, TEVA, Marck Sharp and Dohme, Myelo Therapeutics, Macrogenics, Eisai, Puma, Lilly, Novartis, and AstraZeneca and he received grant from BioTech, Cepheid, and Novartis.

Prof. Frank Förster received honoraria for consulting and/or lectures from Roche, Novartis, AstraZeneca, Eisai, Lilly, Pfizer, Tesaro, MSD, and Celgene.

Dr. med. Christian Kurbacher received honoraria for a consulting or advisory role from Amgen, Axios, Eli Lilly, Hilotherm, Mundipharma, NewCo, Novartis, Pfizer, Riemser, Roche, Tesaro; research funding from AstraZeneca, Axios, MSD Sharp and Dohme, NewCo, Novartis, Pfizer, PharmaMar, Riemser, and Seattle Genetics; honoraria from Amgen, Eli Lilly, Novartis, Mundipharma, Pfizer, PharmaMar, Riemser, Roche, and Tesaro; and a travel grant, accommodations and expenses from Amgen, Hexal, Pfizer, PharmaMar, Tesaro, and TEVA Oncology.

Dr. med. Lothar Müller received travel grants from octapharm and Medac.

Prof. Volkmar Müller received honoraria from Amgen, Astra Zeneca, Celgene, Daiichi-Sankyo, Eisai, Pfizer, MSD, Novartis, Roche, and Teva and consultancy honoraria from Genomic Health, Hexal, Roche, Pierre Fabre, Amgen, ClinSol, Novartis, MSD, Daiichi-Sankyo, Eisai, Lilly, Tesaro, and Nektar.

Dr. med. Isabel Radke received honoraria and/or travel grants from Amgen, Astra Zeneca, Celgene, Genomic Health, Novartis, Pierre Fabre, Pfizer, Roche, and Teva.

Prof. Eugen Ruckhäberle received honoraria from Amgen, AstraZeneca, Pharma Mar, Celgene, Daiichi Sankyo, Eisai, GSK, Lilly, MSD, Novartis, Pfizer, Pierre Fabre, Riemser, Roche, Sandoz/ Hexal, Seattle Genetics, Tesaro Bio, Clovis Oncology, and Teva.

Dr. med. Iris Scheffen received honoraria from Amgen, Celgene, MSD, Novartis, Pfizer, and Roche.

Dr. med. Moritz Schwoerer received honoraria for adboard participation from Roche.

Dr. med. Dieter Steinfeld-Birg received honoraria for studies and/or consulting from Amgen, Hexal, Roche, Teva, and Novartis.

Dr. med. Katja Ziegler-Löhr received honoraria from Celgene, Novartis, Oncovis, Roche, Tesaro.

\section{Author Contributions}

This paper is based on the discussion of the authors after the ABC5 Consensus Conference. This work was reviewed and checked by all of the authors, and authors bear the sole responsibility for the final release of the contents of this paper.

\section{References}

1 Ditsch N, Untch M, Thill M, Müller V, Janni W, Albert US, et al. AGO recommendations for the diagnosis and treatment of patients with early breast cancer: update 2019 . Breast Care. 2019;14:224-5.

2 Cardoso F, Senkus E, Costa A, Papadopoulos E, Aapro M, André F, et al. ESO-ESMO 4th international consensus guide-lines for advanced breast cancer (ABC4). Ann Oncol. 2018 Aug;29(8):1634-57.

3 Harbeck N, Lüftner D, Marschner N, Untch M, Augustin D, Briest S, et al. ABC4 Consensus: Assessment by a German Group of Experts. Breast Care (Basel). 2018 Mar;13(1): 48-58.

4 Cardoso F, Costa A, Norton L, Cameron D, Cufer T, Fallowfield L, et al. 1st International consensus guidelines for advanced breast cancer (ABC 1). Breast. 2012 Jun;21(3):242-52.

5 Cardoso F, Costa A, Norton L, Senkus E, Aapro M, André F, et al.; European School of Oncology; European Society of Medical Oncology. ESO-ESMO 2nd international consensus guidelines for advanced breast cancer (ABC2). Breast. 2014 Oct;23(5):489-502.

6 Cardoso F, Costa A, Senkus E, Aapro M, André $\mathrm{F}$, Barrios $\mathrm{CH}$, et al. 3rd ESO-ESMO international consensus guidelines for Advanced Breast Cancer (ABC 3). Breast. 2017 Feb;31:244-59.
7 ESMO. ESMO Guidelines Methodology. [cited 2019 Nov]. Available from: www.esmo. org/Guidelines/ESMO-Guidelines-Methodology.

8 Stockler MR, Harvey VJ, Francis PA, Byrne MJ, Ackland SP, Fitzharris B, et al. Capecitabine versus classical cyclophosphamide, methotrexate, and fluorouracil as firstline chemotherapy for advanced breast cancer. J Clin Oncol. 2011 Dec;29(34):4498-504.

9 Cazzaniga ME, Biganzoli L, Cortesi L, et al.; Metronomic Chemotherapy in Advanced Breast Cancer Study Group. Treating advanced breast cancer with metronomic chemo-therapy: what is known, what is new and what is the future? OncoTargets Ther. 2019; 12:2989-97.

10 Cazzaniga ME, Pinotti G, Montagna E, Amoroso D, Berardi R, Butera A, et al.; VICTOR Study Group. Metronomic chemotherapy for advanced breast cancer patients in the real world practice: final results of the VICTOR- 6 study. Breast. 2019 Dec;48:7-16.

11 De Iuliis F, Salerno G, Taglieri L, Lanza R, Scarpa S. On and off metronomic oral vinorelbine in elderly women with advanced breast cancer. Tumori. 2015 Jan-Feb;101(1):30-5.
12 Fedele P, Marino A, Orlando L, Schiavone P, Nacci A, Sponziello F, et al. Efficacy and safety of low-dose metronomic chemotherapy with capecitabine in heavily pretreated patients with metastatic breast cancer. Eur J Cancer. 2012 Jan;48(1):24-9.

13 Krajnak S, Battista M, Brenner W, Almstedt K, Elger T, Heimes AS, et al. Explorative Analysis of Low-Dose Metronomic Chemotherapy with Cyclophosphamide and Methotrexate in a Cohort of Metastatic Breast Cancer Patients. Breast Care (Basel). 2018 Aug;13(4):272-6.

14 Langkjer ST, Kenholm J, Jensen JD, Wedervang $K$, Brixen AT, Grunnet $M$, et al. The NAME trial: a direct comparison of classical oral Navelbine versus Metronomic Navelbine in metastatic breast cancer. Future Oncol. 2019 Aug; 15(22):2561-9.

15 Maur M, Omarini C, Piacentini F, Fontana A, Pettorelli E, Cascinu S. Metronomic capecitabine effectively blocks leptomeningeal carcinomatosis from breast cancer: a case report and literature review. Am J Case Rep. 2017 Feb;18:208-11.

16 Montagna E, Bagnardi V, Cancello G, Sangalli C, Pagan E, Iorfida M, et al. Metronomic Chemotherapy for First-Line Treatment of Metastatic Triple-Negative Breast Cancer: A Phase II Trial. Breast Care (Basel). 2018 Jul; 13(3):177-81. 
17 Masci G, Losurdo A, Gandini C, Garassino I, di Tommaso L, Torrisi R, et al. Low-dose "metronomic chemotherapy" with oral cyclophosphamide and methotrexate in metastatic breast cancer: a case report of extraordinarily prolonged clinical benefit. Ecancermedicalscience. 2012;6:275.

18 Gray R, Bhattacharya S, Bowden C, Miller K, Comis RL. Independent review of E2100: a phase III trial of bevacizumab plus paclitaxel versus paclitaxel in women with metastatic breast cancer. J Clin Oncol. 2009 Oct;27(30) 4966-72.

19 Miller K, Wang M, Gralow J, Dickler M, Cobleigh M, Perez EA, et al. Paclitaxel plus bevacizumab versus paclitaxel alone for metastatic breast cancer. N Engl J Med. 2007 Dec; 357(26):2666-76.

20 Robert NJ, Diéras V, Glaspy J, Brufsky AM, Bondarenko I, Lipatov ON, et al. RIBBON-1: randomized, double-blind, placebo-controlled, phase III trial of chemotherapy with or without bevacizumab for first-line treatment of human epidermal growth factor receptor 2-negative, locally recurrent or metastatic breast cancer. J Clin Oncol. 2011 Apr; 29(10):1252-60.

21 Im SA, Lu YS, Bardia A, Harbeck N, Colleoni M, Franke F, et al. Overall Survival with Ribociclib plus Endocrine Therapy in Breast Cancer. N Engl J Med. 2019 Jul;381(4):307-16.

22 Slamon D, Neven P, Chia S, et al. Overall survival results of the Phase III MON-ALEESA-3 trial of postmenopausal patients with hormone receptor-positive human-epidermal growth factor-2-negative advanced breast cancer treated with fulvestrant plus/minus ribociclib. Ann Oncol. 2019;30 suppl 5:v851934.

23 ESMO. Guidelines. [cited 2019 Nov]. Available from: www.esmo.org/guidlines/esmomcbs.

24 Cherny NI, Sullivan R, Dafni U, Kerst JM, Sobrero A, Zielinski C, et al. A standardised, generic, validated approach to stratify the magnitude of clinical benefit that can be anticipated from anti-cancer therapies: the European Society for Medical Oncology Magnitude of Clinical Benefit Scale (ESMO-MCBS). Ann Oncol. 2015 Aug;26(8):1547-73.

25 Cherny NI, Dafni U, Bogaerts J, Latino NJ, Pentheroudakis G, Douillard JY, et al. ESMOMagnitude of Clinical Benefit Scale version 1.1. Ann Oncol. 2017 Oct;28(10):2340-66.

26 Hartkopf AD, Huober J, Volz B, Nabieva N, Taran FA, Schwitulla J, et al. Treatment landscape of advanced breast cancer patients with hormone receptor positive HER2 negative tumors: data from the German PRAEGNANT breast cancer registry. Breast. 2018 Feb;37: 42-51.

27 Borstkanker Onderzoek Groep. Endocrine therapy plus CDK4/6 in first or second line for hormone (SONIA) receptor positive advanced breast cancer. https://clinicaltrials. gov/ct2/show/study/NCT03425838.
28 André F, Ciruelos E, Rubovszky G, Campone M, Loibl S, Rugo HS, et al.; SOLAR-1 Study Group. Alpelisib for PIK3CA-mutated, hormone receptor-positive advanced breast cancer. N Engl J Med. 2019 May;380(20):192940.

29 Park YH, Kim TY, Kim GM, Jung KH, Kang SY, Park IH, et al. A randomized phase II study of palbociclib plus exemestane with GNRH agonist versus capecitabine in premenopausal women with hormone receptorpositive metastatic breast cancer (KCSG-BR 15-10, NCT02592746). J Clin Oncol. 2019;37: 1007.

30 Martín M, Zielinski C, Ruíz-Borrego $M$, et al. Results from PEARL study (GEICAM/2013-02_CECOG/BC.1.3.006): A phase 3 trial of Palbociclib (PAL) in combination with endocrine therapy (ET) versus Capecitabine (CAPE) in hormonal receptor (HR)-positive/human epidermal growth factor receptor (HER) 2-negative metastatic breast cancer (MBC) patients (pts) whose disease progressed on aromatase inhibitors (AIs). San Antonio Breast Cancer Symposium 2019; GS2-07.

31 Mehta RS, Barlow WE, Albain KS, Vandenberg TA, Dakhil SR, Tirumali NR, et al. Overall Survival with Fulvestrant plus Anastrozole in Metastatic Breast Cancer. N Engl J Med. 2019 Mar;380(13):1226-34.

32 Bergh J, Jönsson PE, Lidbrink EK, Trudeau M, Eiermann W, Brattström D, et al. FACT: an open-label randomized phase III study of fulvestrant and anastrozole in combination compared with anastrozole alone as first-line therapy for patients with receptor-positive postmenopausal breast cancer. J Clin Oncol. 2012 Jun;30(16):1919-25.

33 Johnston SR, Kilburn LS, Ellis P, Dodwell D, Cameron D, Hayward L, et al.; SoFEA investigators. Fulvestrant plus anastrozole or placebo versus exemestane alone after progression on non-steroidal aromatase inhibitors in postmenopausal patients with hormone-receptor-positive locally advanced or metastatic breast cancer (SoFEA): a composite, multicentre, phase 3 randomised trial. Lancet Oncol. 2013 Sep;14(10):989-98.

34 Saura C, Oliveira M, Feng YH. Neratinib + capecitabine vs lapatinib + capecitabine in patients with HER2+ metastatic breast cancer previously treated with $\geq 2$ HER2-directed regimens: findings from the multinational, randomized, phase III NALA trial. J Clin Oncol. 2019 May;37(15):1002.

35 Pivot X, Manikhas A, Żurawski B, Chmielowska E, Karaszewska B, Allerton R, et al. CEREBEL (EGF111438): A Phase III, Randomized, Open-Label Study of Lapatinib Plus Capecitabine Versus Trastuzumab Plus Capecitabine in Patients With Human Epidermal Growth Factor Receptor 2-Positive Metastatic Breast Cancer. J Clin Oncol. 2015 May;33(14):1564-73.

36 Schmid P, Adams S, Rugo HS, Schneeweiss A, Barrios $\mathrm{CH}$, Iwata $\mathrm{H}$, et al.; IMpassion 130 Trial Investigators. Atezolizumab and nab-paclitaxel in advanced triple-negative breast cancer. N Engl J Med. 2018 Nov;379(22):210821.
37 Cortes J, Lipatov O, Im S, et al. KEYNOTE-119: phase 3 study of pembrolizumab versus single-agent chemotherapy for metastatic triple-negative breast cancer. Ann Oncol. 2019;30 suppl 5:v85-934.

38 Robson M, Im SA, Senkus E, Xu B, Domchek SM, Masuda N, et al. Olaparib for metastatic breast cancer in patients with a germline BRCA mutation. N Engl J Med. 2017 Aug; 377(6):523-33.

39 Litton JK, Rugo HS, Ettl J, Hurvitz SA, Gonçalves A, Lee KH, et al. Talazoparib in patients with advanced breast cancer and a germline BRCA mutation. N Engl J Med. 2018 Aug; 379(8):753-63.

40 Lux M, Lewis K, Rider A, et al. BRCA1/2 testing in HER2- advanced breast cancer (ABC): results from the European component of a multi-country real world study. Ann Oncol. 2019(30):v99-v103.

41 Dieras VC, Han HS, Kaufman B, Wildiers H, Friedlander M, Ayoub JP, et al. Phase 3 study of veliparib with carboplatin and paclitaxel in HER2-negaive advanced/metastatic gBRCAassociated breast cancer. Ann Oncol. 2019; 30:v851-934.

42 German Breast Group. BMBC (GBG 79). Available from: www.gbg.de/de/studien/ brainmet.php.

43 ESMO: SMO clinical practice guidelines: supportive and palliative care. [cited 2019 Nov]. Available from: https://www.esmo.org/ guidelines/Supportive-and-Palliative-Care.

44 Hortobagyi GN, Van Poznak C, Harker WG, Gradishar WJ, Chew H, Dakhil SR, et al. Continued Treatment Effect of Zoledronic Acid Dosing Every 12 vs 4 Weeks in Women With Breast Cancer Metastatic to Bone: The OPTIMIZE-2 Randomized Clinical Trial. JAMA Oncol. 2017 Jul;3(7):906-12.

45 Awan AA, Hutton B, Hilton J, Mazzarello S, Van Poznak C, Vandermeer L, et al. De-escalation of bone-modifying agents in patients with bone metastases from breast cancer: a systematic review and meta-analysis. Breast Cancer Res Treat. 2019 Aug;176(3):507-17.

46 Leitlinienprogramm Onkologie. S3 guideline "Early Detection, Diagnostics, Therapy and Follow-up Care in Breast Cancer." Long Version 4.0. www.leitlinienprogramm-onkologie.de.

47 Deutsche Gesellschaft für Palliativmedizin. Expanded S3 guideline on palliative care for patients with incurable cancer. Long Version 2.0. https://www.dgpalliativmedizin.de/neuigkeiten/august-2019-erweiterte-s3-leitliniepalliativmedizin.html.

48 Dykewicz CA; Centers for Disease Control and Prevention (U.S.); Infectious Diseases Society of America; American Society of Blood and Marrow Transplantation. Summary of the guidelines for preventing opportunistic infections among hematopoietic stem cell transplant recipients. Clin Infect Dis. 2001 Jul;33(2):139-44.
ABC5 Consensus - Assessment by a German Group of Experts
Breast Care 2020;15:82-95

DOI: $10.1159 / 000505957$ 